\title{
ANALISIS KECEPATAN RATA-RATA LALU LINTAS DI RUAS JALAN PILAU AKIBAT KENDARAAN BERBELOK
}

\author{
ANALYSIS OF AVERAGE TRAFFIC SPEED ON THE PILAU ROADSIDE DUE TO TURNING \\ VEHICLES
}

\author{
Nirwana Puspasari \\ Program Studi Teknik Sipil Universitas Muhammadiyah Palangka Raya \\ Korespondensi: nirwana.puspasari@yahoo.com
}

\begin{abstract}
ABSTRAK
Seringkali kita temui adanya beberapa hambatan yang menyebabkan terjadinya konsentrasi lalu lintas di beberapa titik pada suatu ruas jalan yang menyebabkan melambatnya gerakan lalu lintas bahkan sampai berhenti. Konsentrasi arus lalu lintas terjadi di titik-titik persimpangan jalan, seperti salah satunya di persimpangan Pilau-Keruing, dimana lalu lintas yang bergerak di jalan Pilau terpaksa memperlambat kecepatannya ketika arus lalu lintas dari jalan Keruing berbelok kanan memotong arus tersebut. Oleh karena itu sangat penting untuk mengetahui pengaruh gerakan berbelok terhadap kelancaran arus lalu lintas. Pengambilan data dilakukan dengan menurunkan beberapa surveyor ke lapangan untuk mendapatkan data sekunder dan data primer. Selanjutnya analisa kinerja ruas jalan dengan menggunakan Manual Kapasitas Jalan Indonesia 1997. Didapatkan kecepatan rata-rata ruang dari grafik hubungan DS dengan vlv adalah sebesar $\mathrm{vlv}=28 \mathrm{~km} / \mathrm{jam}$. Kecepatan rata-rata dari hasil survei kecepatan di ruas jalan memberikan nilai vlv=29,6 $\mathrm{km} / \mathrm{jam}$ dengan kondisi tanpa adanya rintangan arus berbelok dari arah jalan Keruing ke jalan Pilau, dan $\mathrm{vlv}=25,6 \mathrm{~km} / \mathrm{jam}$ dengan adanya rintangan arus berbelok. Terjadi penurunan waktu tempuh rata-rata sebesar 5,9 detik, dengan perubahan penurunan kecepatan lalu lintas sebesar $4 \mathrm{~km} / \mathrm{jam}$ akibat pengaruh kendaraan berbelok dari jalan Keruing ke jalan Jati.
\end{abstract}

Kata Kunci : hambatan samping, kecepatan ruang rata-rata, kendaraan berbelok, kinerja ruas jalan

\section{ABSTRACT}

Often we encounter several obstacles that cause traffic concentration at several points on a road segment which causes traffic movement to slow down and even stop. Concentration of traffic flow occurs at intersection points, such as one at the Pilau-Keruing intersection, where traffic moving on the Pilau road is forced to slow down when the traffic flow from Keruing road turns right to cut the flow. Therefore, it is very important to know the effect of turning movement on the smooth flow of traffic. Data collection was carried out by sending several surveyors to the field to obtain secondary and primary data. Furthermore, the analysis of road performance using the 1997 Indonesian Road Capacity Manual. The average space speed obtained from the graph of the relationship between $D S$ and $v l v$ is $v l v=28 \mathrm{~km} / \mathrm{hour}$. The average speed from the results of the speed survey on the road section gives a value of $v l v=29.6 \mathrm{~km} / \mathrm{h}$ with conditions without any obstacles to the flow of turning from the Keruing road to the Pilau road, and vlv $=25.6 \mathrm{~km} / \mathrm{h}$ with the presence of turning current obstacles. There was a decrease in average travel time of 5.9 seconds, with a decrease in traffic speed of $4 \mathrm{~km} / \mathrm{hour}$ due to the influence of vehicles turning from Keruing road to Jati road.

Keywords: road segment performance, side friction, space mean speed, vehicle turns 


\section{PENDAHULUAN}

\section{Latar Belakang}

Arus lalu lintas yang lancar tentunya sangat diharapkan oleh para pengguna jalan, karena tentu saja akan memperpendek waktu tempuh. Tetapi pada kenyataannya seringkali kita temui adanya beberapa hambatan yang menyebabkan terjadinya konsentrasi lalu lintas di beberapa titik pada suatu ruas jalan yang menyebabkan melambatnya gerakan lalu lintas bahkan sampai berhenti.

Konsentrasi arus lalu lintas tersebut terjadi terutama di titik-titik persimpangan jalan, seperti salah satunya di persimpangan Pilau-Keruing, dimana lalu lintas yang bergerak di jalan Pilau terpaksa memperlambat kecepatannya ketika arus lalu lintas dari jalan Keruing berbelok kanan memotong arus tersebut. Oleh karena itu sangat penting untuk mengetahui pengaruh gerakan berbelok tersebut terhadap kelancaran arus lalu lintas di ruas jalan Pilau tersebut.

\section{Tujuan}

Tujuan penelitian ini untuk mengetahui pengaruh gerakan lalu lintas di titik persimpangan Pilau-Keruing terhadap kecepatan rata-rata ruang pada ruas jalan Pilau dengan kajian MKJI dan survei di lapangan.

\section{Manfaat}

Manfaat yang diharapkan adalah:

1. Membantu membuktikan secara kuantitatif pengaruh gerakan lalu lintas di titik persimpangan terhadap kecepatan rata-rata lalu lintas dengan metode MKJI dan survei kecepatan di ruas jalan.

2. Memberikan wawasan baru bagi masyarakat tentang pentingnya tertib berlalu lintas.

\section{TINJAUAN PUSTAKA}

\section{Hambatan Samping}

Hambatan samping disebabkan oleh 4 (empat) jenis kejadian yang masing-masing memiliki nilai bobot, yaitu :
a. Pejalan kaki (bobot $=0,5)$
b. Kendaraan keluar/masuk ke sisi jalan (bobot $=$ $0,7)$
c. Kendaraan bergerak lambat (bobot $=0,4)$
d. Kendaraan parkir/berhenti $($ bobot $=1,0)$

Frekwensi setiap kejadian hambatan samping dicacah dalam rentang 100 meter ke kiri dan 100 meter ke kanan potongan melintang jalan yang diamati, lalu dikalikan dengan bobot masingmasing.

\section{Terbobot $=$ Frek $_{P E D} \times 0,5+$ Frek $_{B E V} \times 0,7+$ Frek $_{S W V} \times 0,4+$ Frek $_{S V}$}

Frekwensi terbobot menentukan kelas hambatan samping :
a. < 100 (Kelas : amat rendah /VL)
b. 100-299 (Kelas : rendah/L)
c. $300-499$ (Kelas : Sedang/M)
d. 500-899 (Kelas : tinggi/H)
e. >900 (Kelas : sangat tinggi/VH)

\section{Volume lalu lintas}

Adalah jumlah kendaraan yang melewati suatu titik (surveyor) tiap satuan waktu.

\section{$Q=q \times \operatorname{emp}$}

Tabel 1. Ekivalen Mobil Penumpang

\begin{tabular}{|l|c|c|c|c|}
\hline Tipe jalan : & \multirow{2}{*}{$\begin{array}{l}\text { Arus lalu } \\
\text { Jalan tak } \\
\text { terbagi }\end{array}$} & $\begin{array}{l}\text { lintas total } \\
\text { dua arah } \\
\text { (q) } \\
\text { (kend/jam) }\end{array}$ & HV & \multicolumn{3}{|c|}{\begin{tabular}{l} 
EMP \\
\cline { 3 - 5 }
\end{tabular}} & \multicolumn{2}{|c|}{$\begin{array}{l}\text { Lebar jalur lalu } \\
\text { lintas (meter) }\end{array}$} \\
\cline { 3 - 5 } & 0 & 1,3 & $0,5 \mathrm{~m}$ & $>6 \mathrm{~m}$ \\
\hline $\begin{array}{l}\text { Dua-lajur } \\
\text { tak- terbagi } \\
\text { (2/2 UD) }\end{array}$ & $\geq 1800$ & 1,2 & 0,35 & 0,25 \\
\hline $\begin{array}{l}\text { Empat-lajur } \\
\text { tak-terbagi } \\
\text { (4/2 UD) }\end{array}$ & 0 & 1,3 & \multicolumn{2}{|c|}{0,4} \\
\hline
\end{tabular}

\section{Dimana :}

$\mathrm{Q}=$ volume lalu lintas dalam smp/jam $\mathrm{q}=$ volume lalu lintas dalam kendaraan/jam emp=ekivalen mobil penumpang berdasarkan komposisi kendaraan

\section{Kapasitas Jalan}

Adalah arus lalu lintas maksimum yang dapat melintas dengan stabil pada suatu potongan melintang jalan pada keadaan (geometrik, pemisah arah, komposisi lalu lintas dan lingkungan) tertentu.

$$
C=C_{o} \times F C_{W} \times F C_{S P} \times F C_{S F} \times F C_{C S}
$$

\section{Dimana :}

C $=$ Kapasitas (smp/jam)

$C_{\mathrm{o}} \quad=$ Kapasitas dasar (smp/jam) 
$F C_{W}=$ Faktor penyesuai lebar jalan

$F C_{S P}=$ Faktor pemisah arah

$F C_{S F}=$ Faktor hambatan samping

$F C_{C S}=$ Faktor ukuran kota

Tabel 2. Kapasitas Dasar

\begin{tabular}{|l|c|c|}
\hline \multicolumn{1}{|c|}{ Tipe Jalan } & $\begin{array}{c}\text { Kapasitas Dasar } \\
\text { (smp/jam) }\end{array}$ & Catatan \\
\hline $\begin{array}{l}\text { Empat-lajur } \\
\text { terbagi atau jalan } \\
\text { satu arah }\end{array}$ & 1650 & Per lajur \\
\hline $\begin{array}{l}\text { Empat-lajur tak } \\
\text { terbagi }\end{array}$ & 1500 & Per lajur \\
\hline $\begin{array}{l}\text { Duas-lajur tak- } \\
\text { terbagi }\end{array}$ & 2900 & $\begin{array}{l}\text { Total dua } \\
\text { arah }\end{array}$ \\
\hline
\end{tabular}

Tabel 3. Faktor Lebar Jalan

\begin{tabular}{|c|c|c|}
\hline \multirow{2}{*}{ Tipe Jalan } & $\begin{array}{c}\text { Lebar jalur lalu } \\
\text { lintas efektif } \\
(\mathrm{Wc}) \text { meter }\end{array}$ & $\mathbf{F C}_{W}$ \\
\hline $\begin{array}{c}\text { Empat-lajur } \\
\text { terbagi atau jalan } \\
\text { satu-arah }\end{array}$ & Per lajur : 3,00 & 0,92 \\
\cline { 2 - 3 } & 3,25 & 0,96 \\
\cline { 2 - 3 } & 3,50 & 1,00 \\
\cline { 2 - 3 } $\begin{array}{l}\text { Empat-lajur tak- } \\
\text { terbagi }\end{array}$ & 3,75 & 1,04 \\
\cline { 2 - 3 } & Per lajur : 3,00 & 1,08 \\
\cline { 2 - 3 } & 3,25 & 0,91 \\
\cline { 2 - 3 } & 3,50 & 0,95 \\
\cline { 2 - 3 } $\begin{array}{c}\text { Dua-lajur } \\
\text { terbagi }\end{array}$ & 3,75 & 1,00 \\
\hline & 4,00 & 1,05 \\
\hline & 5 & 1,09 \\
\hline & 7 & 0,56 \\
\hline & 8 & 0,87 \\
\hline & 9 & 1,00 \\
\hline & 10 & 1,14 \\
\hline & 11 & 1,29 \\
\hline
\end{tabular}

Tabel 4. Faktor Pemisah Arah

\begin{tabular}{|c|l|c|c|c|c|c|}
\hline \multicolumn{2}{|c|}{$\begin{array}{c}\text { Pemisah arah } \\
\text { SP \% }\end{array}$} & $\begin{array}{c}50- \\
50\end{array}$ & $55-45$ & $60-$ & $65-35$ & $\begin{array}{c}70- \\
40\end{array}$ \\
\hline FC $_{\text {SP }}$ & $\begin{array}{l}\text { Dua- } \\
\text { lajur } \\
\text { 2/2 }\end{array}$ & 1,00 & 0,97 & 0,94 & 0,91 & 0,88 \\
\cline { 2 - 7 } & $\begin{array}{l}\text { Empat- } \\
\text { lajur } \\
\text { 4/2 }\end{array}$ & 1,00 & 0,985 & 0,97 & 0,955 & 0,94 \\
\hline
\end{tabular}

Tabel 5 Faktor Hambatan Samping dengan bahu jalan.

\begin{tabular}{|c|c|c|c|c|c|}
\hline \multirow[t]{3}{*}{$\begin{array}{l}\text { Tipe } \\
\text { Jalan }\end{array}$} & \multirow[t]{3}{*}{$\begin{array}{c}\text { Kelas } \\
\text { hambatan } \\
\text { samping }\end{array}$} & \multicolumn{4}{|c|}{$\begin{array}{l}\text { Faktor penyesuaian untuk } \\
\text { hambatan sampaing dan } \\
\text { lebar bahu FCsf }\end{array}$} \\
\hline & & \multicolumn{4}{|c|}{ Lebar bahu efektif Ws } \\
\hline & & $\leq 0,5$ & 1,00 & 1,5 & $\geq 2,0$ \\
\hline \multirow[t]{5}{*}{$4 / 2 \mathrm{D}$} & VL & 0,96 & 0,98 & 1,01 & 1,03 \\
\hline & $\mathrm{L}$ & 0,94 & 0,97 & 1,00 & 1,02 \\
\hline & M & 0,92 & 0,95 & 0,98 & 1,00 \\
\hline & $\mathrm{H}$ & 0,88 & 0,92 & 0,95 & 0,98 \\
\hline & VH & 0,84 & 0,88 & 0,92 & 0,96 \\
\hline \multirow[t]{5}{*}{$4 / 2$ UD } & VL & 0,96 & 0,99 & 1,01 & 1,03 \\
\hline & $\mathrm{L}$ & 0,94 & 0,97 & 1,00 & 1,02 \\
\hline & M & 0,92 & 0,95 & 0,98 & 1,00 \\
\hline & $\mathrm{H}$ & 0,87 & 0,91 & 0,94 & 0,98 \\
\hline & $\mathrm{VH}$ & 0,80 & 0,86 & 0,90 & 0,95 \\
\hline \multirow{5}{*}{$\begin{array}{l}2 / 2 \text { UD } \\
\text { atau } \\
\text { Jalan } \\
\text { satu arah }\end{array}$} & VL & 0,94 & 0,96 & 0,99 & 1,01 \\
\hline & $\mathrm{L}$ & 0,92 & 0,94 & 0,97 & 1,00 \\
\hline & M & 0,89 & 0,92 & 0,95 & 0,98 \\
\hline & $\mathrm{H}$ & 0,82 & 0,86 & 0,90 & 0,95 \\
\hline & $\mathrm{VH}$ & 0,73 & 0,79 & 0,85 & 0,91 \\
\hline
\end{tabular}

Tabel 6. Faktor Ukuran Kota

\begin{tabular}{|c|c|}
\hline $\begin{array}{c}\text { Ukuran Kota (Juta } \\
\text { penduduk) }\end{array}$ & $\begin{array}{c}\text { Faktor penyesuaian untuk } \\
\text { ukuran kota }\end{array}$ \\
\hline$<0,1$ & 0,86 \\
$0,1-0,5$ & 0,90 \\
$0,5-1,0$ & 0,94 \\
$1,0-3,0$ & 1,00 \\
$>3,0$ & 1,04 \\
\hline
\end{tabular}

\section{Derajat Jenuh}

Adalah ratio volume lalu lintas (Q) terhadap kapasitas (C), yang digunakan sebagai penentu perilaku lalu lintas pada suatu ruas jalan.

$$
D S=\frac{Q}{C}
$$

$$
\begin{aligned}
& \text { Dimana : } \\
& \mathrm{DS}=\text { Derajat Jenuh } \\
& \mathrm{Q}=\text { Volume lalu lintas (smp/jam) } \\
& \mathrm{C} \quad=\text { Kapasitas (smp/jam) }
\end{aligned}
$$

\section{Kecepatan Arus Bebas}

Adalah kecepatan pada saat tingkatan arus nol, sesuai dengan kecepatan yang akan dipilih pengemudi seandainya mengendarai kendaraan bermotor tanpa halangan kendaraan bermotor lain di jalan.

$$
\boldsymbol{F V}=\left(F V_{o}+F V_{w}\right) \times F F V_{S F} \times F F V_{C S}
$$


Dimana :

FV: Kecepatan arus bebas kendaraan ringan pada kondisi lapangan ( $\mathrm{km} / \mathrm{jam})$

Fvo: Kecepatan arus bebas dasar kendaraan ringan pada jalan dan alinyemen yang diamati (km/jam)

FVw : Faktor penyesuaian kecepatan akibat lebar jalur lalu lintas (km/jam)

FVsf : Faktor penyesuaian hambatan samping dan lebar bahu/jarak kerb ke penghalang

FFVcs: Faktor penyesuaian ukuran kota.

Tabel 7. Kecepatan Arus Bebas Dasar (FVo)

\begin{tabular}{|c|c|c|c|c|}
\hline \multirow{2}{*}{$\begin{array}{c}\text { Tipe } \\
\text { Jalan }\end{array}$} & \begin{tabular}{l} 
Kend. \\
\cline { 2 - 5 } \\
Ringan
\end{tabular} & $\begin{array}{l}\text { Kend. } \\
\text { Berat } \\
\text { (HV) }\end{array}$ & $\begin{array}{l}\text { Sepeda } \\
\text { motor } \\
\text { (MC) }\end{array}$ & $\begin{array}{l}\text { Semua } \\
\text { kendaraan(rata- } \\
\text { rata) }\end{array}$ \\
\hline $\begin{array}{c}\text { 6/2D } \\
\text { atau } \\
3 / 1\end{array}$ & 61 & 52 & 48 & 57 \\
\hline $\begin{array}{c}4 / 2 \mathrm{D} \\
\text { atau } \\
2 / 1\end{array}$ & 57 & 50 & 47 & 55 \\
\hline $\begin{array}{c}4 / 2 \\
\text { UD }\end{array}$ & 53 & 46 & 43 & 51 \\
\hline $\begin{array}{c}\text { 2/2 } \\
\text { UD }\end{array}$ & 44 & 40 & 40 & 42 \\
\hline
\end{tabular}

Tabel 8. Penyesuaian Kecepatan Arus Bebas

Untuk lebar Jalur Lalu Lintas (FVw)

\begin{tabular}{|c|c|c|}
\hline Tipe Jalan & $\begin{array}{c}\text { Lebar jalur lalu } \\
\text { lintas efektif }(\mathrm{Wc}) \\
(\text { meter })\end{array}$ & $\begin{array}{c}\text { FVw } \\
(\mathrm{km} / \mathrm{jam})\end{array}$ \\
\hline Empat lajur & Per lajur : 3,00 & -4 \\
terbagi atau & 3,25 & -2 \\
Jalan satu arah & 3,50 & 0 \\
& 3,75 & 2 \\
& 4,00 & 4 \\
\hline Empat lajur tak & Per lajur : 3,00 & -4 \\
terbagi & 3,25 & -2 \\
& 3,50 & 0 \\
& 3,75 & 2 \\
& 4,00 & 4 \\
\hline Dua lajur tak & Total : 5 & $-9,5$ \\
terbagi & 6 & 0 \\
& 7 & 3 \\
& 8 & 4 \\
& 9 & 6 \\
& 10 & 7 \\
\hline
\end{tabular}

Tabel 9. Penyesuaian Kecepatan Arus Bebas Untuk Hambatan Samping (FFVsf)

1. Jalan dengan Bahu Jalan

\begin{tabular}{|c|c|c|c|c|c|}
\hline \multirow[t]{2}{*}{$\begin{array}{c}\text { Tipe } \\
\text { Jalan }\end{array}$} & \multirow[t]{2}{*}{$\begin{array}{c}\text { Kelas } \\
\text { Hambatan } \\
\text { Samping } \\
\text { (SFC) }\end{array}$} & \multicolumn{4}{|c|}{$\begin{array}{l}\text { Faktor penyesuaian untuk } \\
\text { hambatan samping dan lebar } \\
\text { bahu } \\
\text { Lebar bahu efektif rata-rata } \\
\text { (dalam meter) Ws }\end{array}$} \\
\hline & & $\leq 0,5$ & 1,0 & 1,5 & $\geq 2,0$ \\
\hline $\begin{array}{l}\text { Empat } \\
\text { lajur } \\
\text { terbagi } \\
4 / 2 \mathrm{D}\end{array}$ & $\begin{array}{l}\text { Sangat } \\
\text { rendah } \\
\text { Rendah } \\
\text { Sedang } \\
\text { Tinggi } \\
\text { Sangat } \\
\text { tinggi }\end{array}$ & $\begin{array}{l}0,98 \\
0,94 \\
0,89 \\
0,84\end{array}$ & $\begin{array}{l}1,00 \\
0,97 \\
0,93 \\
0,88\end{array}$ & $\begin{array}{l}1,02 \\
1,00 \\
0,96 \\
0,92\end{array}$ & $\begin{array}{l}1,03 \\
1,02 \\
0,99 \\
0,96\end{array}$ \\
\hline $\begin{array}{l}\text { Empat } \\
\text { lajur } \\
\text { tak } \\
\text { terbagi } \\
4 / 2 \text { UD }\end{array}$ & $\begin{array}{l}\text { Sangat } \\
\text { rendah } \\
\text { Rendah } \\
\text { Sedang } \\
\text { Tinggi } \\
\text { Sangat } \\
\text { tinggi }\end{array}$ & $\begin{array}{l}0,98 \\
0,93 \\
0,87 \\
0,80\end{array}$ & $\begin{array}{l}1,00 \\
0,96 \\
0,91 \\
0,86\end{array}$ & $\begin{array}{l}1,02 \\
0,99 \\
0,94 \\
0,90\end{array}$ & $\begin{array}{l}1,03 \\
1,02 \\
0,98 \\
0,95\end{array}$ \\
\hline $\begin{array}{l}\text { Dua } \\
\text { lajur } \\
\text { tak } \\
\text { terbagi } \\
2 / 2 \text { UD } \\
\text { atau } \\
\text { Jalan } \\
\text { satu } \\
\text { arah }\end{array}$ & $\begin{array}{l}\text { Sangat } \\
\text { rendah } \\
\text { Rendah } \\
\text { Sedang } \\
\text { Tinggi } \\
\text { Sangat } \\
\text { tinggi }\end{array}$ & $\begin{array}{l}0,96 \\
0,91 \\
0,82 \\
0,73\end{array}$ & $\begin{array}{l}1,01 \\
\\
0,98 \\
0,93 \\
0,86 \\
0,79\end{array}$ & $\begin{array}{l}1,01 \\
0,99 \\
0,96 \\
0,90 \\
0,85\end{array}$ & $\begin{array}{l}1,00 \\
0,99 \\
0,95 \\
0,91\end{array}$ \\
\hline
\end{tabular}

2. Jalan dengan Kerb

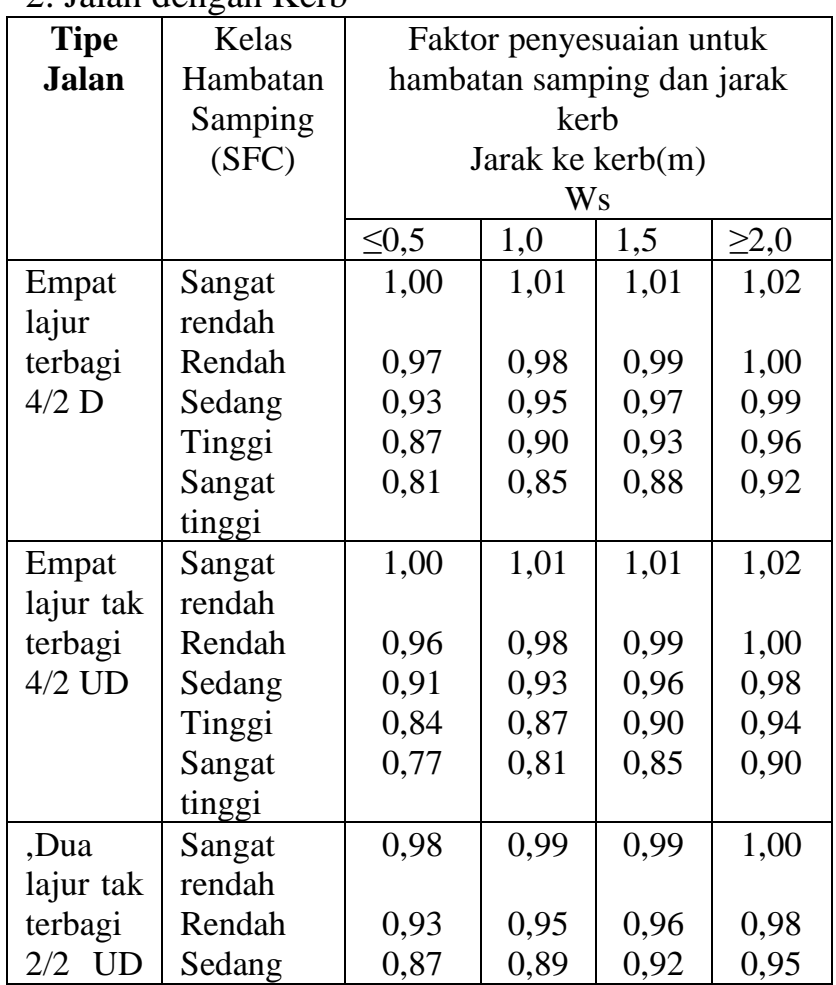




\begin{tabular}{|c|c|c|c|c|c|}
\hline \multirow[t]{2}{*}{$\begin{array}{c}\text { Tipe } \\
\text { Jalan }\end{array}$} & \multirow[t]{2}{*}{$\begin{array}{l}\text { Kelas } \\
\text { Hambatan } \\
\text { Samping } \\
\text { (SFC) }\end{array}$} & \multicolumn{4}{|c|}{$\begin{array}{c}\text { Faktor penyesuaian untuk } \\
\text { hambatan samping dan jarak } \\
\text { kerb } \\
\text { Jarak ke kerb(m) } \\
\text { Ws }\end{array}$} \\
\hline & & $\leq 0,5$ & 1,0 & 1,5 & $\geq 2,0$ \\
\hline atau & Tinggi & 0,78 & 0,81 & 0,84 & 0,88 \\
\hline $\begin{array}{l}\text { Jalan } \\
\text { satu } \\
\text { arah }\end{array}$ & $\begin{array}{l}\text { Sangat } \\
\text { tinggi }\end{array}$ & 0,68 & 0,72 & 0,77 & 0,82 \\
\hline
\end{tabular}

Tabel 10. Penyesuaian Kecepatan Arus Bebas Untuk Ukuran Kota (FFVcs)

\begin{tabular}{|c|c|}
\hline $\begin{array}{c}\text { Ukuran Kota (jlh } \\
\text { penduduk) }\end{array}$ & $\begin{array}{c}\text { Faktor Penyesuaian } \\
\text { Untuk Ukuran Kota }\end{array}$ \\
\hline$<0,1$ & 0,90 \\
$0,1-0,5$ & 0,93 \\
$0,5-1,0$ & 0,95 \\
$1,0-3,0$ & 1,00 \\
$>3$ & 1,03 \\
\hline
\end{tabular}

\section{Kecepatan Rata-rata Ruang (Vlv)}

Adalah kecepatan kendaraan untuk menempuh ruas yang dianalisis. Nilai kecepatan rata-rata ruang dipengaruhi oleh derajat jenuh (DS) dan kecepatan arus bebas (FV).

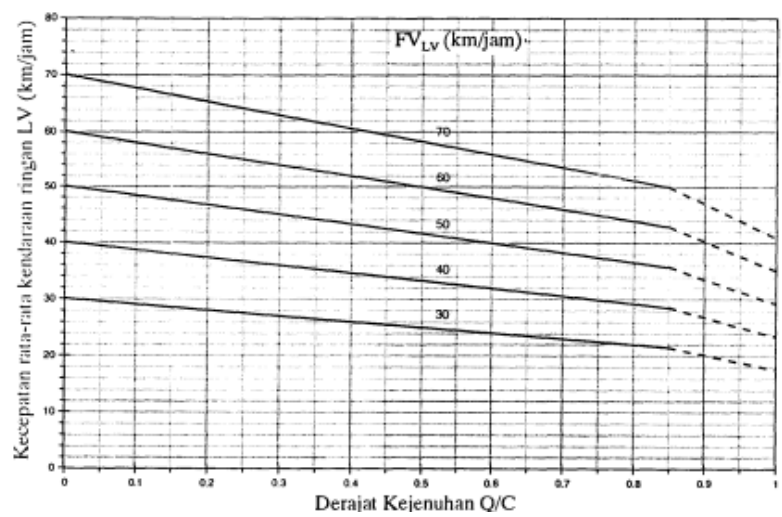

Gambar 1. Grafik Hubungan DS dan Vlv

\section{METODE PENELITIAN}

\section{Lokasi Penelitian}

Lokasi penelitian dilakukan di jalan Pilau dan persimpangan Pilau-Keruing di kota Palangka Raya.

\section{Metode Pengambilan data}

Pengambilan data dilakukan dengan menurunkan beberapa surveyor ke lapangan untuk mendapatkan data sekunder dan data primer.

\section{Data Primer}

Pengumpulan dilakukan dengan cara observasi lapangan, seperti :

a. Melakukan pencacahan volume arus lalu lintas 2 arah dan pencacahan hambatan samping seperti kendaraan bergerak lambat, kendaraan berhenti/parkir, kendaraan keluar masuk sisi jalan dan jumlah pejalan kaki yang berada di segmen jalan yang akan dianalisis.

b. Mengukur geometrik jalan seperti lebar jalan dan lebar bahu jalan.

c. Survei kecepatan rata-rata, dengan mengambil sampel 20 kendaraan.

\section{Data Sekunder}

Data sekunder diperoleh dari instansi yang terkait dengan penelitian ini seperti peta lokasi penelitian dan jumlah penduduk Kota Palangka Raya.

\section{Alat yang Digunakan}

Adapun alat yang digunakan dalam penelitian ini adalah: meteran, patok interval, counter, alat tulis dan laptop.

\section{Pelaksanaan Survey}

Pelaksanaan survei lalu lintas di ruas jalan Pilau dan titik persimpangan dilakukan selama 3 hari, dan dilakukan pada jam puncak sore (15.3017.30)

\section{Tahapan Penelitian}

1. Identifikasi permasalahan

2. Persiapan alat dan tenaga surveyor untuk survey lapangan

3. Pengumpulan data primer dan data sekunder

4. Analisa data :

a. Menghitung volume lalu lintas dan hambatan samping

b. Menghitung kapasitas dan kinerja ruas jalan

c. Menghitung Kecepatan arus bebas dan kecepatan rata-rata ruang

d. Menghitung kecepatan arus di lapangan

5. Menarik Kesimpulan

6. Selesai 


\section{Bagan Alir Penelitian}

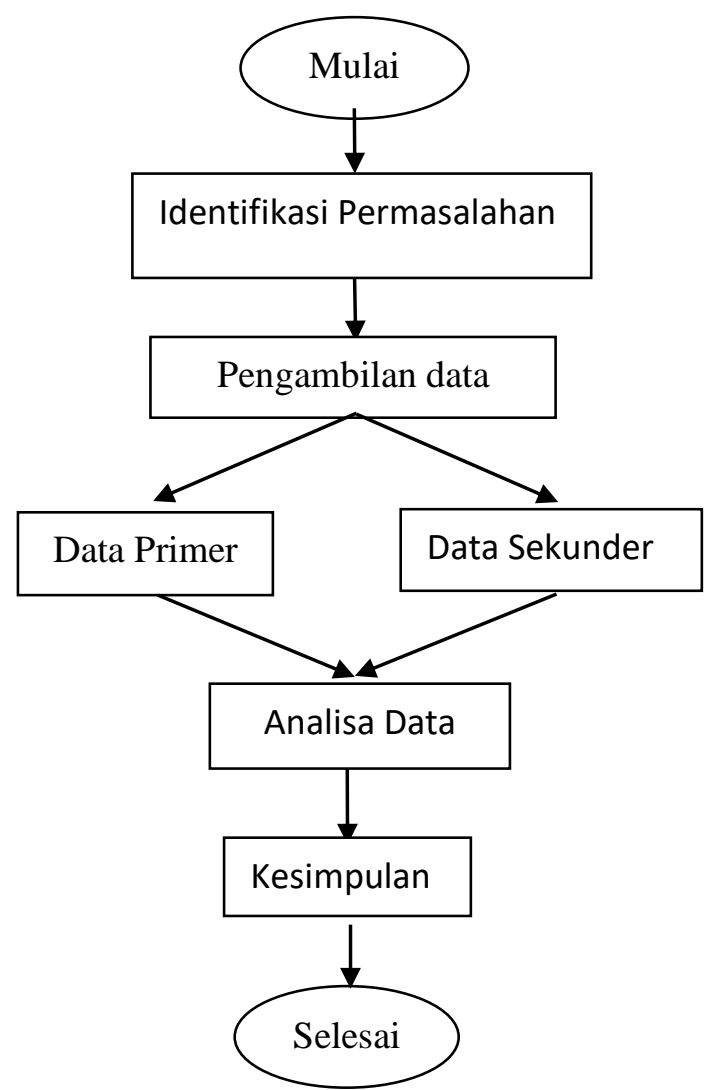

Gambar 2. Diagram Alir Penelitian

\section{ANALISA DAN PEMBAHASAN}

\section{Geometrik Jalan}

Data geometrik jalan sangat diperlukan dalam menganalisa kapasitas dan kecepatan arus bebas. Data geometrik tersebut berupa tipe jalan, lebar jalan dan lebar bahu jalan.

Jalan Pilau termasuk tipe jalan 2/2 UD, yaitu jalan yang memiliki 2 lajur 2 arah dan tidak dipisahkan oleh median jalan. Lebar efektif jalan 5,6 meter dan lebar bahu efektif 1,0 meter.

\section{Hambatan Samping}

Data hambatan samping sangat diperlukan untuk menentukan kelas hambatan samping, yang berfungsi dalam menganalisis kapasitas dan kecepatan arus bebas ruas jalan. Jalan Pilau memiliki aktivitas sisi jalan yang cukup ramai karena adanya pertokoan dan PKL di sisi jalan tersebut.

Dari hasil survey diperoleh data hambatan samping pada jam puncak sore (16.00-17.00) adalah sebagai berikut : a. Pejalan kaki (Ped) : 112 orang

b. Kendaraan keluar masuk sisi jalan (EEV) : 160 kendaraan

c. Kendaraan bergerak lambat (SMV) : 130 kendaraan

d. Kendaraan Parkir (SV) : 82 kendaraan

Berdasarkan data hambatan samping tersebut dapat di hitung bobot kejadian pada ruas jalan Pilau sebagai berikut: $+(82)$

Terbobot $=(112)(0,5)+(160)(0,7)+(130)(0,4)$

Terbobot $=56+112+52+82=302$

Yang menunjukan bahwa kelas hambatan samping pada ruas jalan Pilau adalah termasuk kelas Medium (300-499).

\section{Volume Lalu Lintas (smp/jam)}

Dari hasil survei volume lalu lintas pada ruas jalan Pilau, dapat diketahui bahwa volume lalu lintas tertinggi (kend/jam) yang terjadi pada jam sibuk sore (16.00-17.00) adalah sebagai berikut :

Tabel 11. Hasil Survei Volume Lalu Lintas

\begin{tabular}{|c|c|c|l|l|l|}
\hline ARAH & MC & LV & \multicolumn{1}{|c|}{ MHV } & \multicolumn{2}{|c|}{ TOTAL } \\
\hline A & 220 & 180 & 10 & 410 & \multirow{2}{*}{1022} \\
\hline B & 312 & 293 & 7 & 612 & \\
\hline
\end{tabular}

1. Arah A :

$$
\begin{aligned}
& \mathrm{QA}=(220)(\mathrm{emp} \mathrm{MC})+(180)(\mathrm{emp} \mathrm{LV})+(6) \\
& (\mathrm{emp} \mathrm{MHV}) \\
& \mathrm{QA}=(220)(0,5)+(180)(1)+(10)(1,2) \\
& \mathrm{QA}=110+180+12=302 \mathrm{smp} / \mathrm{jam}
\end{aligned}
$$

2. Arah B :

$\mathrm{QB}=(312)(\mathrm{emp} \mathrm{MC})+(293)(\mathrm{emp} \mathrm{LV})+(7)$ (emp MHV)

$\mathrm{QB}=(312)(0,5)+(293)(1)+(5)(1,2)$

$\mathrm{QB}=156+293+6=455 \mathrm{smp} / \mathrm{jam}$

Volume lalu lintas total dua arah adalah:

$\mathrm{QAB}=\mathrm{QA}+\mathrm{QB}$

$\mathrm{QAB}=302+455=757 \mathrm{smp} / \mathrm{jam}$

\section{Kapasitas Jalan (smp/jam)}

Menghitung Kapasitas ruas jalan dengan cara mengalikan kapasitas dasar dengan 4 faktor kapasitasnya, yaitu faktor lebar jalan, faktor pembagi arah, faktor hambatan samping dan faktor ukuran kota berikut ini :

$C_{\circ}=2900 \mathrm{smp} / \mathrm{jam}$ untuk tipe jalan 2/2 UD 
$F C_{W}=0.72$ untuk lebar jalan 5,6 meter

$F C_{S P}=0,94$ untuk pemisah arah $40: 60$

$F C_{S F}=0,92$ untuk tipe jalan $2 / 2 \mathrm{UD}$, lebar bahu efektif 1 meter dan kelas hambatan samping Medium.

$F C_{C S}=0,90$ untuk ukuran kota 100.000-500.000 jiwa

$$
C=C_{o} \times F C_{W} \times F C_{S P} \times F C_{S F} \times F C_{C S}
$$

Maka kapasitas ruas jalan Pilau adalah:

$\mathrm{C}=2900 \mathrm{smp} / \mathrm{jam} \times 0,72 \times 0,94 \times 0,92 \times 0,9$

$\mathrm{C}=1625 \mathrm{smp} / \mathrm{jam}$

\section{Derajat Jenuh (DS)}

Derajat Jenuh dapat dihitung dengan cara membagi volume lalu lintas tertinggi total 2 arah (smp/jam) dengan kapasitas (smp/jam). Diketahui $\mathrm{Q}=757 \mathrm{smp} / \mathrm{jam}$ dan $\mathrm{C}=1625 \mathrm{smp} / \mathrm{jam}$, maka :

$\mathrm{DS}=\mathrm{Q} / \mathrm{C}=757 / 1625=0,47$

\section{Kecepatan Arus Bebas (FV)}

Kecepatan arus bebas dapat dihitung dengan cara menjumlahkan arus bebas dasar dengan faktor lebar kaki masuk simpang, kemudian dikalikan dengan faktor hambatan samping dan faktor ukuran kota.

$\mathrm{FV}=(\mathrm{Fvo}+\mathrm{FV} w) \times$ FFV sf $x$ FFVcs

Faktor kecepatan arus bebas untuk semua kendaraan rata-rata tersebut adalah :

$\mathrm{FVo}=44 \mathrm{~km} / \mathrm{jam}$ untuk semua kendaraan dan jalan tipe $2 / 2$ UD

$\mathrm{FVw}=-5,6$ (hasil interpolasi) untuk lebar jalan 5,6 meter (antara 5-6 meter).

FFVsf $=0,93$ untuk tipe jalan 2/2 UD, lebar bahu 1 meter dan kelas hambatan samping Medium.

FFVcs $=0,93$ untuk ukuran kota kecil $(2900.000$ jiwa), yaitu antara 100.000-500.000 jiwa.

Sehingga kecepatan arus bebas tersebut adalah : $\mathrm{FV}=(\mathrm{Fvo}+\mathrm{FVw}) \times \mathrm{FFV}$ sf $\times \mathrm{FFV} c \mathrm{~s}$

$\mathrm{FV}=(44+(-5,6)) \mathrm{km} / \mathrm{jam} \quad \mathrm{x} \quad 0,93 \times 0,93=33,2$ $\mathrm{km} / \mathrm{jam}$.

\section{Kecepatan Rata-rata Ruang (Vlv)}

Berdasarkan hasil perhitungan derajat jenuh (DS) dan kecepatan arus bebas (FV), maka dengan menggunakan grafik hubungan $\mathrm{DS}=0,47$, $\mathrm{FV}=33,2 \mathrm{~km} / \mathrm{jam}$ maka dapat diketahui besarnya kecepatan rata-rata ruang untuk kendaraan ringan adalah Vlv=28 km/jam.

\section{Kecepatan rata-rata di lapangan}

Hasil Analisa data waktu tempuh rata-rata 20 kendaraan di ruas jalan Pilau tanpa rintangan kendaraan berbelok dari jalan Keruing, diperoleh data pada tabel berikut:

Tabel 12. Hasil analisa data waktu tempuh rata-rata tanpa rintangan kendaraan berbelok

\begin{tabular}{|c|c|c|}
\hline $\begin{array}{c}\text { Panjang Interval } \\
\text { (meter) }\end{array}$ & $\begin{array}{c}\text { Waktu tempuh } \\
\text { rata-rata (detik) }\end{array}$ & $\begin{array}{c}\text { Kecepatan rata- } \\
\text { rata }(\mathrm{m} / \mathrm{dt})\end{array}$ \\
\hline 300 & 36,5 & 8,22 \\
\hline
\end{tabular}

Maka diperoleh kecepatan rata-rata kendaraan dilapangan sebesar:

$$
\mathrm{v}=8,22 \mathrm{~m} / \mathrm{dt} \times(3,6)=29,6 \mathrm{~km} / \mathrm{jam} \text {. }
$$

Dan dari hasil Analisa data waktu tempuh rata-rata 20 kendaraan di ruas jalan Pilau dengan adanya rintangan kendaraan berbelok, diperoleh data seperti pada tabel berikut:

Tabel 13. Hasil analisa data waktu tempuh rata-rata dengan rintangan kendaraan berbelok

\begin{tabular}{|c|c|c|}
\hline $\begin{array}{c}\text { Panjang Interval } \\
\text { (meter) }\end{array}$ & $\begin{array}{c}\text { Waktu tempuh } \\
\text { rata-rata (detik) }\end{array}$ & $\begin{array}{c}\text { Kecepatan rata- } \\
\text { rata (m/dt) }\end{array}$ \\
\hline 300 & 42,4 & 7,1 \\
\hline
\end{tabular}

Maka diperoleh kecepatan rata-rata kendaraan dilapangan sebesar: $\mathrm{v}=7,1 \mathrm{~m} / \mathrm{dt} \times(3,6)=25,6 \mathrm{~km} / \mathrm{jam}$.

\section{PENUTUP}

\section{Kesimpulan}

Dari hasil pengamatan di lapangan, pengolahan data dan hasil analisis dapat disimpulkan bahwa

1. Aktivitas sisi jalan seperti pejalan, kendaraan yang parkir di badan jalan, kendaraan yang keluar masuk sisi jalan dan kendaraan bergerak lambat memberikan pengaruh pada kelas hambatan samping dengan nilai terbobot sebesar 302, yang berarti hambatan samping termasuk kelas Medium (sedang).

2. Kapasitas jalan Pilau dengan lebar jalan 5,6 meter dan lebar bahu efektif 1,0 meter sebesar: $\mathrm{C}=1625 \mathrm{smp} / \mathrm{jam}$. 
3. Hasil perbandingan volume dan kapasitas, di peroleh Derajat Jenuh ruas jalan Pilau sebesar $\mathrm{DS}=0,47$

4. Kecepatan arus bebas sebesar: $F V=33,2 \mathrm{~km} / \mathrm{jam}$.

5. Kecepatan rata-rata ruang dari grafik hubungan DS dengan vlv adalah sebesar vlv $=28 \mathrm{~km} / \mathrm{jam}$.

6. Kecepatan rata-rata dari hasil survei kecepatan di ruas jalan memberikan nilai vlv=29,6 km/jam dengan kondisi tanpa adanya rintangan arus berbelok dari arah jalan Keruing ke jalan Pilau, dan $\mathrm{vlv}=25,6 \mathrm{~km} / \mathrm{jam}$ dengan adanya rintangan arus berbelok. Disini terjadi penurunan waktu tempuh rata-rata sebesar 5,9 detik, dengan perubahan penurunan kecepatan lalu lintas sebesar $4 \mathrm{~km} / \mathrm{jam}$ akibat pengaruh kendaraan berbelok dari jalan Keruing ke jalan Jati.

7. Meskipun derajat jenuh masih dalam kriteria aman, namun akibat Gerakan berbelok kendaraan, tetap saja memberikan kontribusi penurunan waktu tempuh kendaraan yang pada akhirnya mengurangi kecepatan rata-rata kendaraan di ruas jalan.

\section{Saran}

Karena Gerakan berbelok dari Keruing ke Pilau tidak mungkin dihindari, maka setidaknya pengguna jalan tidak memberikan masalah tambahan terhadap kelancaran lalu lintas seperti parkir sembarangan di badan jalan, dan sebaiknya tertib dalam berlalu lintas salah satunya dengan penggunaan lampu sign kendaraan yang baik dan benar ketika akan berbelok.

\section{DAFTAR PUSTAKA}

Alamsyah, A. A, (2005), Rekayasa Lalu Lintas, UMM, Malang

Direktorat Jenderal Bina Marga, (1970), Peraturan Perencanaan Geometrik Jalan Raya, Departemen Pekerjaan Umum, Jakarta

Direktorat Jenderal Bina Marga, (1997), Manual Kapasitas Jalan Indonesia, Departemen. Pekerjaan Umum, Jakarta

Direktorat Jenderal Perhubungan Darat, (1997), Pedoman Perencanaan dan Pengoperasian Lalu Lintas di Wilayah Perkotaan, Rekayasa Lalu Lintas, Departemen Perhubungan, Jakarta.

Hobbs, W. B, (1995), Perencanaan dan Teknik Lalu Lintas, Edisi kedua, Universitas Gadjah Mada, Yogyakarta

Miro, Fidel, (2004), Perencanaan Transportasi, Erlangga, Jakarta,
Warpani, S., (1993), Rekayasa Lalu Lintas, Bhratara, Jakarta, 